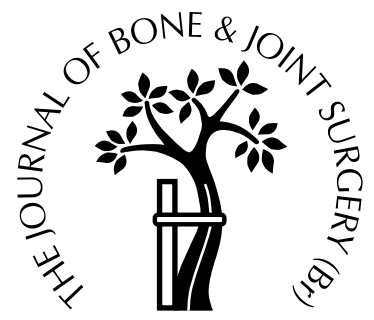

\title{
Reconstruction of the lateral ligaments of the ankle using solvent-dried and gamma-irradiated allogeneic fascia lata
}

\author{
Ken Nakata, Konsei Shino, Shuji Horibe, Takashi Natsu-ume, \\ Tatsuo Mae, Takahiro Ochi \\ From Osaka University Medical School, Japan
}

$\mathbf{W}^{\mathrm{e}}$ e have described a method of anatomical reconstruction of the lateral ligaments of the ankles with instability using allogeneic fascia lata dried with solvents and sterilised with gamma irradiation. Twenty ankles of 20 patients were assessed objectively and subjectively after a mean follow-up of 4.2 years (3.1 to 10). The result was excellent in 12 $(60 \%)$, good in seven $(35 \%)$ and fair in one $(5 \%)$; none had a poor result. Stress radiography showed that the angle of talar tilt improved from $12.3 \pm 4.2^{\circ}$ (mean $\pm \mathrm{SD}$ ) to $5.9 \pm 3.0^{\circ}$ and that the anterior drawer distance decreased from $9.2 \pm 3.9 \mathrm{~mm}$ to $4.4 \pm 2.5 \mathrm{~mm}$. Neither infection nor limitation of movement occurred after operation. Fascia lata allografts provide a good alternative to autogenous grafts such as the peroneus brevis tendon.

J Bone Joint Surg [Br] 2000;82-B:579-82.

Received 14 July 1999; Accepted after revision 26 November 1999

Inversion injuries of the ankle frequently occur in daily life or when playing sport and may cause rupture of the lateral ligaments. Although patients with this common injury are treated conservatively in the acute phase, some, especially if untreated or neglected, develop chronic lateral instability. Recurrent ankle sprains cause synovitis and damage to cartilage, ${ }^{1,2}$ and result in degenerative joint disease. ${ }^{3}$ Surgical treatment may be necessary for patients with chronic lateral instability of the ankle $\mathrm{e}^{4,5}$ and many operative procedures for reconstruction of the lateral ligaments have been described. ${ }^{6-12}$

K. Nakata, MD, PhD, Assistant Professor

T. Mae, Postgraduate Student

T. Ochi, MD, PhD, Professor

Department of Orthopaedic Surgery, Osaka University Medical School, 2-2 Yamadaoka, Suita, Osaka 55, Japan.

K. Shino, MD, PhD, Professor

Division of Physical Therapy, Osaka Prefectural College of Health Sciences, 3-7-30 Habikino, Habikino, Osaka 583, Japan.

$\mathrm{S}$. Horibe, $\mathrm{MD}, \mathrm{PhD}$, Director of Orthopaedic Sports Medicine

T. Natsu-ume, MD, PhD, Orthopaedic Surgeon

Osaka Rosai Hospital, 1179-3 Nagasone-cho, Sakai, Osaka 591, Japan.

Correspondence should be sent to Dr K. Shino.

(C)2000 British Editorial Society of Bone and Joint Surgery

0301-620X/00/410368\$2.00

VOL. 82-B, No. 4, MAY 2000
For anatomical reconstruction, the ruptured ligaments can be replaced with autogenous tissues such as fascia lata, $^{6}$ tendons $^{7-10}$ and periosteum, ${ }^{11}$ or with allogeneic materials such as fresh-frozen tendon allografts. ${ }^{12}$ The use of allografts eliminates morbidity at the donor site. Although fresh-frozen allografts have been used successfully for reconstruction of ligaments, ${ }^{12-15}$ there are potential disadvantages such as the risk of transmission of disease and difficulties with storage and handling of the grafts. Dehydration of grafts by drying with solvents and gamma irradiation may be one solution to the problem. We describe the medium-term result of reconstruction of the lateral ligaments of the ankle with allogeneic fascia lata dried with solvent and gamma-irradiated, in patients with chronic instability of the lateral ligaments.

\section{Patients and Methods}

Patients with chronic symptoms of instability of the ankle had a manual stress assessment which included both anterior drawer and inversion tests. Stress radiographs were also taken to provide an accurate record of the degree of instability. There were 22 patients with a positive manual stress test and positive stress radiographs, who wished to undertake strenuous activities but had instability of the ankle. They received reconstruction of the anterior talofibular ligament (ATFL) and the calcaneofibular ligament (CFL) using allogeneic fascia lata grafts dried with solvent and gamma-irradiated. Of these, 20 (91\%) returned for follow-up three years or more after operation and were included in our study.

All had a history of two or more injuries to the ankle during sporting activities including soccer, basketball, volleyball, and gymnastics, or during daily activities such as walking on rough ground or descending stairs. They all had a sense of instability because of repetitive sprains of the involved ankle. Five complained of pain and/or tenderness at the anteromedial joint space and ten had tenderness around the distal end of the fibula. The mean period from the initial injury to surgery was 2.6 years $(0.8$ to 7.0$)$. The mean age of the patients at operation was 20.2 years (15 to 31 ) and the mean period of follow-up was 4.2 years (3.1 to 10).

Operative technique. A curved skin incision was made 
from the anterior margin of the lateral malleolus to the distal tip of the fibula. The subcutaneous tissues were divided and the ATFL and CFL exposed. If the CFL was elongated, but thick and continuous, it was repaired by proximal advancement and only the ATFL was reconstructed. Of the 20 patients, $13(65 \%)$ had reconstruction of both the ATFL and the CFL. The ATFL was reconstructed anatomically by a pull-out suture of a graft through bone tunnels in the talus and the lateral malleolus. A tunnel $4.5 \mathrm{~mm}$ in diameter was made in the lateral aspect of the neck of the talus where the ATFL is attached, and passed through to the medial side. Another tunnel was also created in the anterior aspect of the lateral malleolus at the site of fixation of the ATFL, and drilled to the posterior and proximal portion of the distal fibula (Fig. 1). If it was necessary to reconstruct the CFL, the third bone tunnel was drilled at the tubercle of the calcaneus, and passed to the medial aspect. A fourth bone tunnel was made for the CFL from the tip of the lateral malleolus in a posterior and proximal direction (Fig. 1).

After one end of the graft has been passed through the bone tunnel and fixed using a small button on the medial wall of the talus and the calcaneus, isometricity is checked through the range of ankle movement and the graft fixed with sutures around a screw post under manual tension. Care is taken to place more than $1 \mathrm{~cm}$ of the graft in each bony tunnel.

After operation, the ankle is immobilised for three weeks. Partial weight-bearing is then initiated followed by full weight-bearing at six weeks. Strenuous activity is not allowed until five months after surgery.

Graft preparation. The graft used was commercially available allogeneic fascia lata which had been dehydrated by drying with a solvent and sterilised by gamma irradiation (Tutoplast Fascia lata; Biodynamics International, Erlangen, Germany). A strip $1.5 \mathrm{~cm}$ wide and $5 \mathrm{~cm}$ long was used for the ATFL or the CFL, respectively. The graft

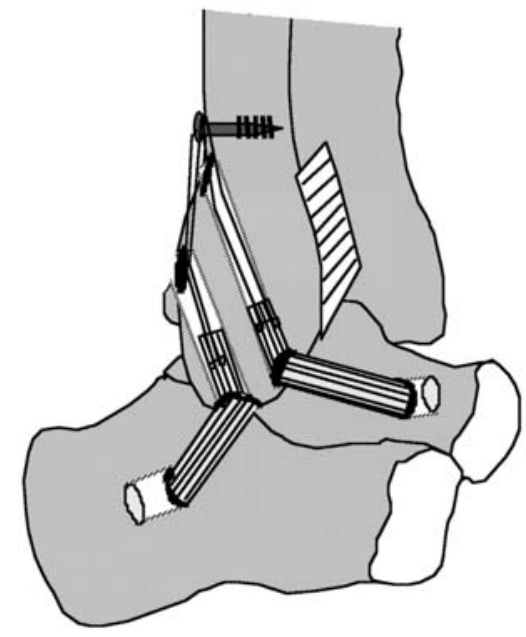

Fig. 1

Diagram showing reconstruction of the anterior talofibular and the calcaneofibular ligaments.

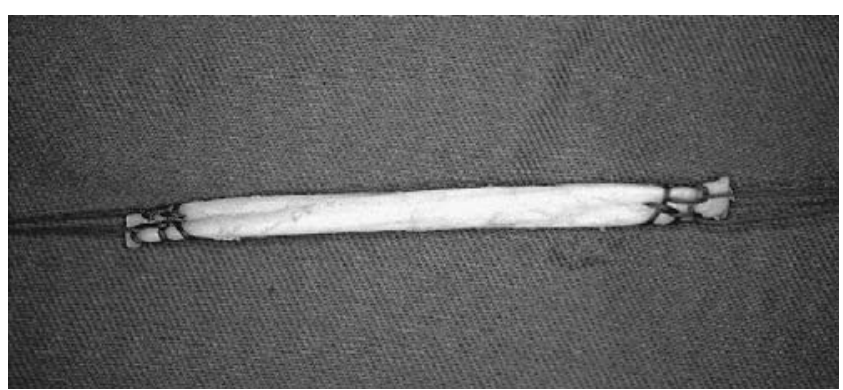

Fig. 2

Appearance of the graft. A piece of allogeneic lyophilised and gammairradiated fascia lata $1.5 \mathrm{~cm}$ wide and $5 \mathrm{~cm}$ long was reconstituted in sterile saline with antibiotics and rolled up to $4.5 \mathrm{~mm}$ in diameter.

was reconstituted in sterile saline with antibiotics for 10 to 20 minutes at room temperature and rolled to $4.5 \mathrm{~mm}$ in diameter. Two non-absorbable \#2 braided polyester sutures were placed at each end (Fig. 2).

Evaluation. Subjective evaluation was carried out according to the criteria of Good, Jones and Livingstone (Table I). ${ }^{96}$ All patients were assessed by manual stress testing and stress radiography using a commercially available stress $\mathrm{x}$ ray device (Telos SE, Hungen, Germany) under $150 \mathrm{~N}$ force without anaesthesia. The talar tilt angle and the anterior drawer distance were measured on stress radiographs. The paired Student $t$-test was used for statistical analysis.

\section{Results}

There were no instances of postoperative infection or immunological rejection. According to the criteria of Good et al, ${ }^{16}$ 12 patients $(60 \%)$ had an excellent and seven (35\%) a good outcome. One complained of slight pain over the anteromedial joint space after strenuous activity and was graded as fair. Manual stress testing showed that 19 patients were stable in both the anterior drawer and the inversion tests. The mean angle of talar tilt was $12.3 \pm 4.2^{\circ}(\mathrm{SD})$ before and $5.9 \pm 3.0^{\circ}$ after surgery. The mean angle for the contralateral ankle was $6.3 \pm 4.5^{\circ}$ (Fig. 3a). The mean anterior drawer distance improved from $9.2 \pm 3.9 \mathrm{~mm}$ to $4.4 \pm 2.5 \mathrm{~mm}$ after surgery. For the contralateral ankle it was $4.6 \pm 3.1 \mathrm{~mm}$ (Fig. 3b). Statistical analysis showed that both the talar tilt and the anterior drawer distance were significantly decreased after operation $(\mathrm{p}<0.05)$. There were no signs of osteoarthritis on the radiographs of the final follow-up and no patient had limitation of the range of ankle movement.

Table I. Grading of symptoms according to Good et $\mathrm{al}^{16}$

\begin{tabular}{ll}
\hline Grade & Symptoms \\
\hline Excellent & $\begin{array}{l}\text { Full activity, including strenuous sport } \\
\text { No pain, swelling or giving way }\end{array}$ \\
Good & $\begin{array}{l}\text { Occasional aching only after strenuous exercise } \\
\text { No giving way or feeling of apprehension }\end{array}$ \\
Fair & $\begin{array}{l}\text { No giving way but some remaining apprehension } \\
\text { and takes care when walking on rough ground }\end{array}$ \\
Poor & $\begin{array}{l}\text { Recurrent instability and giving way in normal } \\
\text { activities, with episodes of pain and swelling }\end{array}$ \\
\hline
\end{tabular}

THE JOURNAL OF BONE AND JOINT SURGERY 

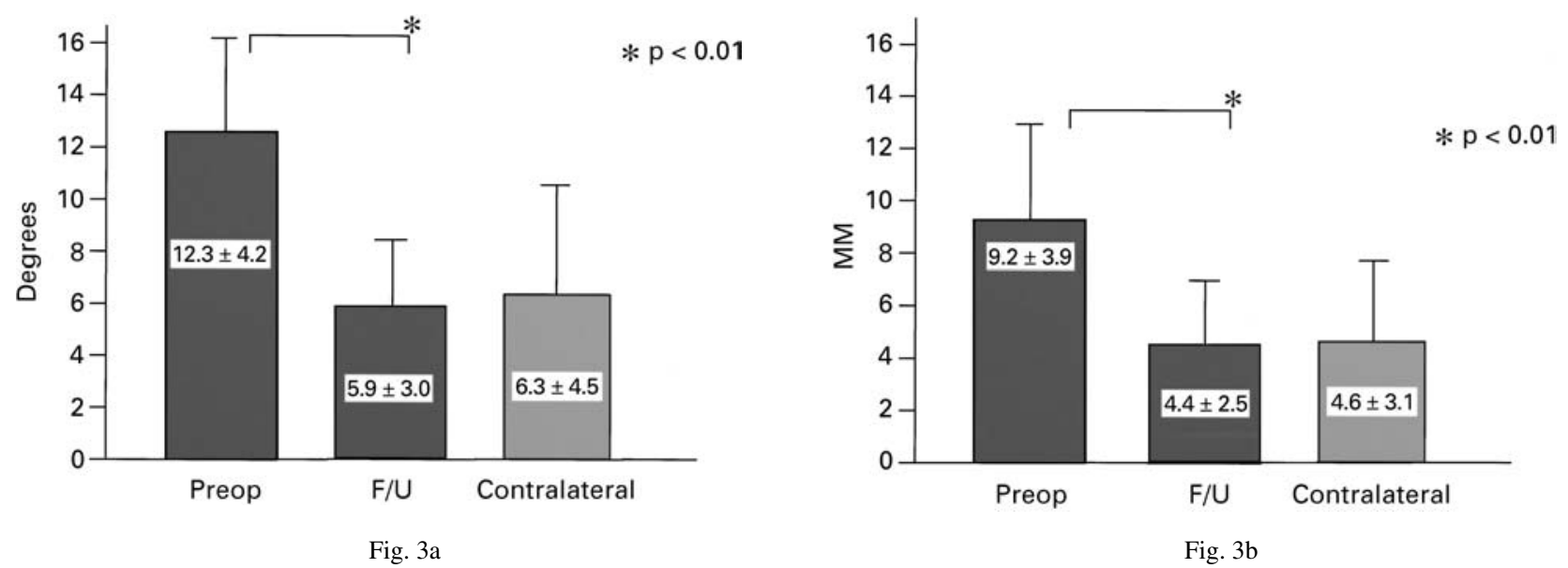

Results of stress radiography, showing the mean values for a) talar tilt and b) the anterior drawer test.

\section{Discussion}

Fresh injuries to the lateral ligaments of the ankle are usually treated conservatively and the healing potential is good. Like Snook, Chrisman and Wilson ${ }^{17}$ we believe that early treatment of ankle sprains by immobilisation, using a plaster cast or a brace, makes it unnecessary to reconstruct the lateral ligaments. Some patients, however, especially if untreated or neglected, develop chronic abnormal laxity of the ATFL and CFL, with recurrent sprains. Our indication for reconstruction of the ligament was disabling recurrent instability of the ankle. All patients in our study had considerable functional impairment before surgery and all failed to respond to conservative treatment, including physiotherapy and bracing.

Many procedures for the treatment of chronic injury to the lateral ligaments have been described ${ }^{6-12}$ and these can be divided into three categories. The first is tenodesis using the autogenous peroneus tendon. Watson-Jones, ${ }^{7}$ Evans, ${ }^{8}$ and Chrisman and Snook ${ }^{9}$ described reconstruction of the ATFL or ATFL and CFL using the peroneus brevis tendon. These procedures, however, do not reconstruct the ATFL and/or CFL in the anatomical position and thus theoretically cannot achieve physiological kinetics of the ankle, ${ }^{18}$ causing limitation of ankle movement. ${ }^{9,19-22}$

The second category consists of operations which use an autogeneous free graft or a pedicled graft such as fascia lata, ${ }^{6}$ the free half of the peroneus tendon, ${ }^{10}$ or periosteum. ${ }^{11}$ Colville, Marder and Zarins, ${ }^{23}$ and Burks and Morgan $^{24}$ emphasised the importance of anatomical reconstruction from the biomechanical point of view. Their biomechanical analysis showed that reconstruction of the lateral ligament using bone tunnels reproduced the anatomical orientation of both the AFTL and CFL, and that the reconstructed ligaments are resistant to anterior displacement, internal rotation, and talar tilt without restricting subtalar joint movement. These procedures still required the sacrifice of normal tissue and weakened the donor
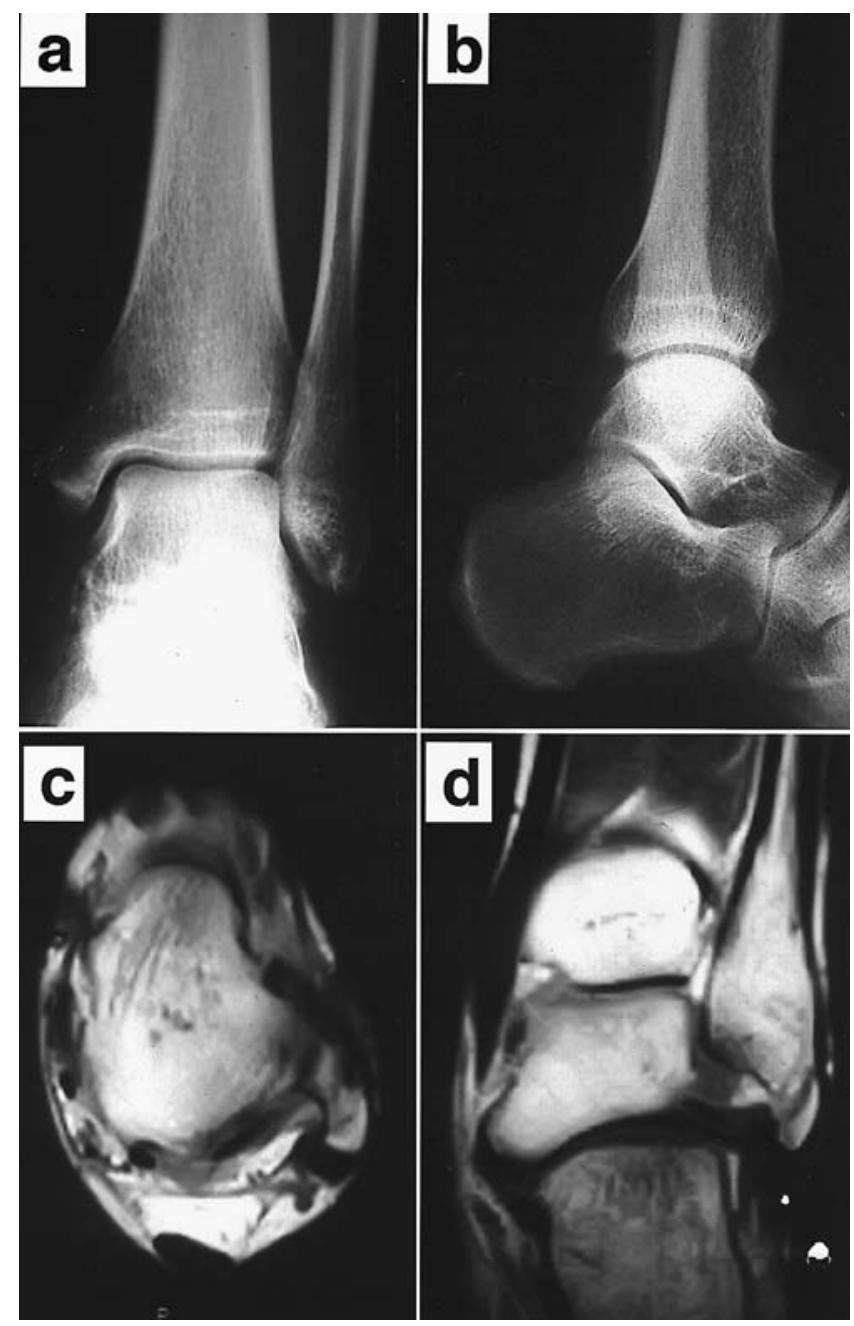

Fig. 4

Ten years after operation the subjective assessment by a patient of his operated ankle was excellent and he had no complaints. Radiographs (a, b) showed no osteoarthritic changes while MRI revealed c) the graft as a low-intensity signal and d) a signal in the fibular bone tunnel which was similar to that of normal bone marrow. 
tissue. This is a significant consideration if the peroneus tendon is harvested, because this muscle is antagonistic to supination of the foot which is important for the prevention of a sprain in inversion. ${ }^{17}$

The third category consists of anatomical reconstruction using allogeneic grafts. As mentioned by Olson et al, ${ }^{25}$ the use of allografts provides a good alternative to autografts for reconstruction of ligaments, is commonly undertaken and the reported rates of success are high. ${ }^{12-15}$ Although our results using fresh-frozen allografts were satisfactory and without any complications, ${ }^{12}$ there are potential disadvantages with the risk of transmission and difficulties with storage and handling of the grafts. The processing of allografts by drying with solvents makes the handling of the graft and storage easy, and gamma irradiation devitalises viruses.

The study by Hinton et $\mathrm{al}^{26}$ suggested that commercially available fascia lata dehydrated with solvent was a more suitable grafting material from the biomechanical point of view than freeze-dried specimens obtained from tissue banks. Although Maeda et $\mathrm{al}^{27}$ and Gibbons et $\mathrm{al}^{28}$ reported that drying with solvents and gamma irradiation had adverse effects on the initial mechanical properties of allografts, a more recent study by Maeda et al ${ }^{29}$ showed that this weakness had disappeared by four weeks after transplantation. Evidence has also been obtained in animal models which indicates that the processes of drying or irradiation temporarily accelerate remodelling of the graft after transplantation. 30,31

In our series, there was no immunological rejection or swelling. As shown in Figure 4, the grafts appeared to have remodelled well after surgery. We believe that the less invasive procedure is a significant advantage of allografts over autogenous grafts.

No benefits in any form have been received or will be received from a commercial party related directly or indirectly to the subject of this article.

\section{References}

1. Larsen E, Aru A. Synovitis in chronically unstable ankles. Acta Orthop Scand 1989;60:340-4.

2. Taga I, Shino K, Inoue M, Nakata K, Maeda A. Articular cartilage lesions in ankles with lateral ligament injury: an arthroscopic study. Am J Sports Med 1993;21:120-6.

3. Harrington KD. Degenerative arthritis of the ankle secondary to longstanding lateral ligament instability. JBone Joint Surg [Am] 1979;61-A:354-61.

4. Peters JW, Trevino SG, Renstrom PA. Chronic lateral ankle instability. Foot Ankle 1991;12:182-91.

5. Karlsson J, Lansinger O. Lateral instability of the ankle joint. Clin Orthop 1992;276:253-61.

6. Elmslie RC. Recurrent subluxation of the ankle joint. Ann Surg 1934;100:364-7.

7. Watson-Jones R. Recurrent forward dislocation of the ankle joint. J Bone Joint Surg [Br] 1952;34-B:519.

8. Evans DL. Recurrent instability of the ankle joint: a method of surgical treatment. Proc R Soc Med 1953;46:343-4.
9. Chrisman OD, Snook GA. Reconstruction of lateral ligament tears of the ankle: an experimental study and clinical evaluation of seven patients treated by a new modification of the Elmslie procedure. J Bone Joint Surg [Am] 1969;51-A:904-12.

10. Colville MR, Grondel RJ. Anatomic reconstruction of the lateral ankle ligaments using a split peroneus brevis tendon graft. Am J Sports Med 1995;23:210-3.

11. Rudert M, Wülker N, Wirth CJ. Reconstruction of the lateral ligaments of the ankle using a regional periosteal flap. J Bone Joint Surg [Br ] 1997; 79-B:446-51.

12. Horibe S, Shino K, Taga I, Inoue M, Ono K. Reconstruction of lateral ligaments of the ankle with allogeneic tendon grafts. $J$ Bone Joint Surg [Br] 1991;73-B:802-5.

13. Shino K, Kimura T, Hirose H, Inoue M, Ono K. Reconstruction of the anterior cruciate ligament by allogeneic tendon graft: an operation for chronic ligamentous insufficiency. JBone Joint Surg $[\mathrm{Br}]$ 1986;68-B:739-46.

14. Indelicato PA, Linton RC, Huegel M. The results of fresh-frozen patellar tendon allografts for chronic anterior cruciate ligament deficiency of the knee. Am J Sports Med 1992;20:118-21.

15. Noyes FR, Barber-Westin SD. Reconstruction of the anterior cruciate ligament with human allograft: comparison of early and later results. J Bone Joint Surg [Am] 1996;78-A:524-37.

16. Good CJ, Jones MA, Livingstone BN. Reconstruction of the lateral ligament of the ankle. Injury 1975;7:63-5.

17. Snook GA, Chrisman OD, Wilson TC. Long-term results of the Chrisman-Snook operation for reconstruction of the lateral ligaments of the ankle. J Bone Joint Surg [Am] 1985;67-A:1-7.

18. Liu SH, Baker CL. Comparison of lateral ankle ligamentous reconstruction procedures. Am J Sports Med 1993;22:313-7.

19. Hollis JM, Blasier RD, Flahiff CM, Hofmann OE. Biomechanical comparison of reconstruction techniques in simulated lateral ankle ligament injury. Am J Sports Med 1995;23:678-82.

20. Tohyama H, Beynnon BD, Pope MH, Haugh LD, Renstrom PA. Laxity and flexibility of the ankle following reconstruction with the Chrisman-Snook procedure. J Orthop Res 1997;15:707-11.

21. Bahr R, Pena F, Shine J, et al. Biomechanics of ankle ligament reconstruction: an in vitro comparison of the Brostrom repair, WatsonJones reconstruction, and a new anatomic reconstruction technique. Am J Sports Med 1997;25:424-32.

22. Rosenbaum D, Becker HP, Wilke HJ, Claes LE. Tenodeses destroy the kinematic coupling of the ankle joint complex: a three-dimensional in vitro analysis of joint movement. JBone Joint Surg $[\mathrm{Br}]$ 1998;80-B:162-8.

23. Colville MR, Marder RA, Zarins B. Reconstruction of the lateral ankle ligaments: a biomechanical analysis. Am J Sports Med 1992;20:594-600.

24. Burks RT, Morgan J. Anatomy of the lateral ankle ligaments. Am J Sports Med 1994;22:72-7.

25. Olson EJ, Harner CD, Fu FH, Silbey MB. Clinical use of fresh, frozen soft tissue allografts. Orthopedics 1992;15:1225-32.

26. Hinton R, Jinnah RH, Johnson C, Warden K, Clarke HJ. A biomechanical analysis of solvent-dehydrated and freeze-dried human fascia lata allografts: a preliminary report. Am J Sports Med 1992;20:607-12.

27. Maeda A, Inoue M, Shino K, et al. Effects of solvent preservation with or without gamma irradiation on the material properties of canine tendon allografts. J Orthop Res 1993;11:181-9.

28. Gibbons MJ, Butler DL, Grood ES, et al. Effects of gamma irradiation on the initial mechanical and material properties of goat bone-patellar tendon-bone allografts. J Orthop Res 1991;9:209-18.

29. Maeda A, Horibe S, Matsumoto N, et al. Solvent-dried and gammairradiated tendon allografts in rats: mechanical and morphological evaluation. J Bone Joint Surg [Br] 1998;80-B:731-6.

30. Nagano J, Shino K, Maeda A, Nakata K, Horibe $S$. The remodelling process of allogeneic and autogenous patellar tendon grafts in rats: a radiochemical study. Arch Orthop Trauma Surg 1996;115:10-6.

31. Toritsuka Y, Shino K, Horibe S, et al. Effect of freeze-drying or gamma-irradiation on remodelling of tendon allograft in a rat model. J Orthop Res 1997;15:294-300. 